\title{
Observations of ionospheric irregularities with different scale sizes during the solar minimum period
}

Meibach-Rosa*; P. R. P.; Muella, M. T. A. H.

Universidade do Vale do Paraíba - UNIVAP

Instituto de Pesquisa e Desenvolvimento - IP\&D

Copyright 2016, SBGf - Sociedade Brasileira de Geofísica

This paper was prepared for presentation during the Ouro Preto, October 25-27, 2016.

Contents of this paper were reviewed by the Technical Committee of the VII Simpósio Brasileiro de Geofísica and do not necessarily represent any position of the SBGf, its officers or members. Electronic reproduction or storage of any part of this paper for commercial purposes without the written consent of the Brazilian Geophysical Society is prohibited.

\section{Abstract}

The solar minimum period of \#24 solar cycle was lower than any previously measured. Was used multitechnique method to investigated occurrence the coexistence of different scale sizes ionospheric irregularities in this deep solar minimum. The ionospheric observations throughout 2008-2010 of Brazilian stations in Palmas $\left(10,2^{\circ} \mathrm{S} ; 48,2^{\circ} \mathrm{W}\right)$ and São José dos Campos $\left(23,2^{\circ} \mathrm{S} ; 45,9^{\circ} \mathrm{W}\right)$ was analyzed to investigate gravity waves and plasma bubbles. Allsky images, ionograms recorded from digital ionosondes, ionospheric amplitude scintillations and rate of total electron content (TEC) variations registered by Global Positioning System (GPS) receivers were deployed to detect the signatures of plasma bubbles on their signals. All-sky images were in operation to investigate the mesosphereionosphere coupling through gravity waves from airglow emissions of $\mathrm{OH}, \mathrm{OI557,7} \mathrm{nm}$ and $01630,0 \mathrm{~nm}$. The main objective of this study is to investigate the morphological characteristics and the physics proprieties related to relevant cases of simultaneous observations.

\section{Introduction}

The solar minimum period between solar cycles (SC) \#23 and \#24, during the years 2007-2009, was the longest and quietest such period since the advent of space-based measurements, and probably the longest and quietest in a century. Also, the first half of SC \#24 has also been the weakest since SC \#14 (Salomom, S.
C., 2013). Ionosonde measurements [Liu et al., 2011, 2012] analysis were found significant decrease in peak ionospheric densities during the cycle 23/24 minimum, compared to previous solar minimum periods. AraujoPradere et al. [2011] also found such decreases an also identified decreases in total electron content (TEC) measured by dual-frequency GPS receivers. This period has been chosen to be investigated by ionospheric irregularities signal measurement analysis. The mesosphere-ionosphere coupling was studied through the analysis of vertical propagation of the gravity waves (GW 's) characteristics. The GWs parameterization occurred by analyzing the airglow images. To mesospheric altitudes, were observed airglow emissions $\mathrm{OH}$ and Ol557.7 nm, and to ionospheric altitudes, $01630.0 \mathrm{~nm}$ emissions. From the calculations of the horizontal and vertical velocities, the analysis of vertical propagation in mesosphere of each GW is based on a comparison of its wavelength values, phase velocity and period estimated. The presence of depletions of large scale in plasma density at the $\mathrm{F}$ region of the ionosphere at low-latitudes, known as plasma bubbles, is attributed to the transequatorial extension of the ionospheric irregularities generated at the magnetic equator (KELLEY, 1989; ABDU; 2001). The main mechanism generating the irregularities at the equatorial $F$ region is attributed to the instability process named as Rayleigh-Taylor. This mechanism act at disturbances introduced at the plasma density in the bottom side of the ionospheric $\mathrm{F}$ region, which then grow until become plasma bubble irregularities. The large scale depletion regions (plasma bubbles) move towards higher altitudes because of the electrodynamic $\mathbf{E} \times \mathbf{B}$ force, and also tend to drift eastward following the normal plasma movement (KELLEY, 1989). The depletion regions become particularly important when extending to latitudes 
of the equatorial ionization anomaly (EIA) where the bubbles intersect the regions of high levels of electron density and steepest plasma density gradients (MUELLA et al., 2010). The night tropical ionosphere presents irregularities in the ionization that can be detected in a very wide spectral range, covering a wide spatial scale, extending from a few centimeters to a hundred of kilometers, and occurring from the bottom side of the ionospheric $\mathrm{F}$ region to altitudes well above the peak of ionization (SCHUNK and NAGY, 2000). Due to the presence of irregularities with different scale sizes, its detection may be conducted from different techniques, which are manifested differently in the records of the instruments. This research study focuses primarily on the investigation of ionospheric irregularities through different radio techniques and also on data optical instruments. In the present investigation we used data obtained with instruments installed in the observatories managed by the group of Physics and Astronomy from UNIVAP, and recorded during the years from 2008 to 2010 .

\section{Method}

Multi-technique observations were in operation to investigate the ionospheric irregularities over an equatorial and a low-latitude station in the Brazilian sector. All-sky images from airglow emissions of $\mathrm{OH}$, Ol557.7 nm Ol630.0 nm were processed by the software UASDA (UNIVAP "All Sky Data Analysis"). Ionograms from digital ionosondes were analyzed by the UDIDA ("Univap Digital lonossonde Data Analisys"). Additionally, by using the software UTECDA ("Univap TEC Data Analysis") was calculated the ROT ("Rate of TEC" lonospheric total electron content) from ground-based Global Positioning System (GPS) receivers. Data from a GPS scintillation monitor managed from Instituto Nacional de Pesquisas Espacias (INPE) were also in operation and used to detect the signatures of ionospheric irregularities on the GPS L1 $(1.575 \mathrm{GHz})$ signal.

\section{Examples}

In Figures 1 to 4 are examples of days with irregularities in the ionosphere observed in the sites of São José dos Campos and Palmas, as registered by the all-sky imagers as plasma depleted structures (Figure 1); the spread- $\mathrm{F}$ in the ionograms (Figure 2) recorded by the digital ionosondes; the S4 amplitude scintillation index obtained for all satellites visible over Cachoeira Paulista, an observatory located $\sim 100 \mathrm{~km}$ far from São José dos Campos (Figure 3); and the rate of TEC estimated at São José dos Campos (Figure 4).

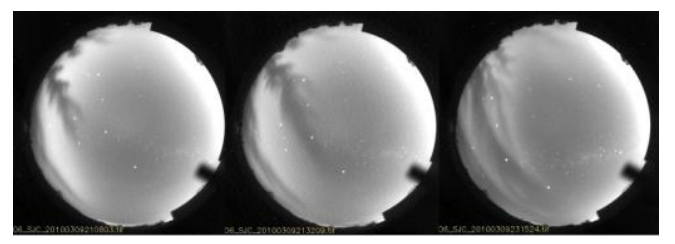

Figure 1 - Plasma depleted structures observed by the all-sky imager at São José dos Campos on March 9, 2010.

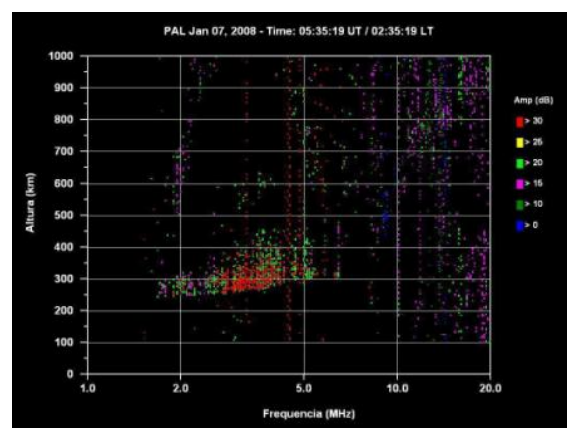

Figure 2 - Spread-F observed in the ionograms over Palmas on January 07, 2008.

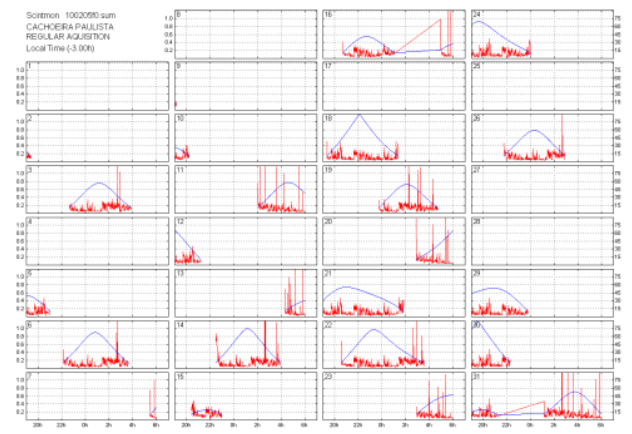

Figure 3 - S4 amplitude scintillation index registered by the GPS receiver at Cahcoeira Paulista on February 5, 2010.

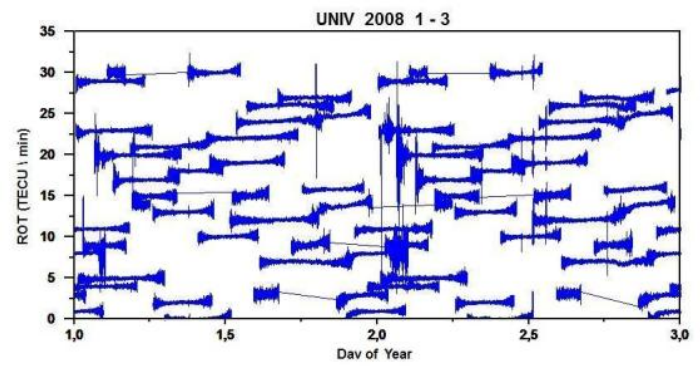


Figure 4 - Rate of TEC (ROT) calculated for all satellites visible by the GPS receiver at São José dos Campos during February 5-6, 2010.

\section{Results}

The following are shown in Figure 5 a case in which events were recorded to identify the occurrence of waves on $\mathrm{OH}$ images $\mathrm{O} 5$ and $\mathrm{O} 6$ the waves on the images on the equatorial station of Palmas. The observed scattering in ionograms indicate simultaneous occurrence of the scintillation.

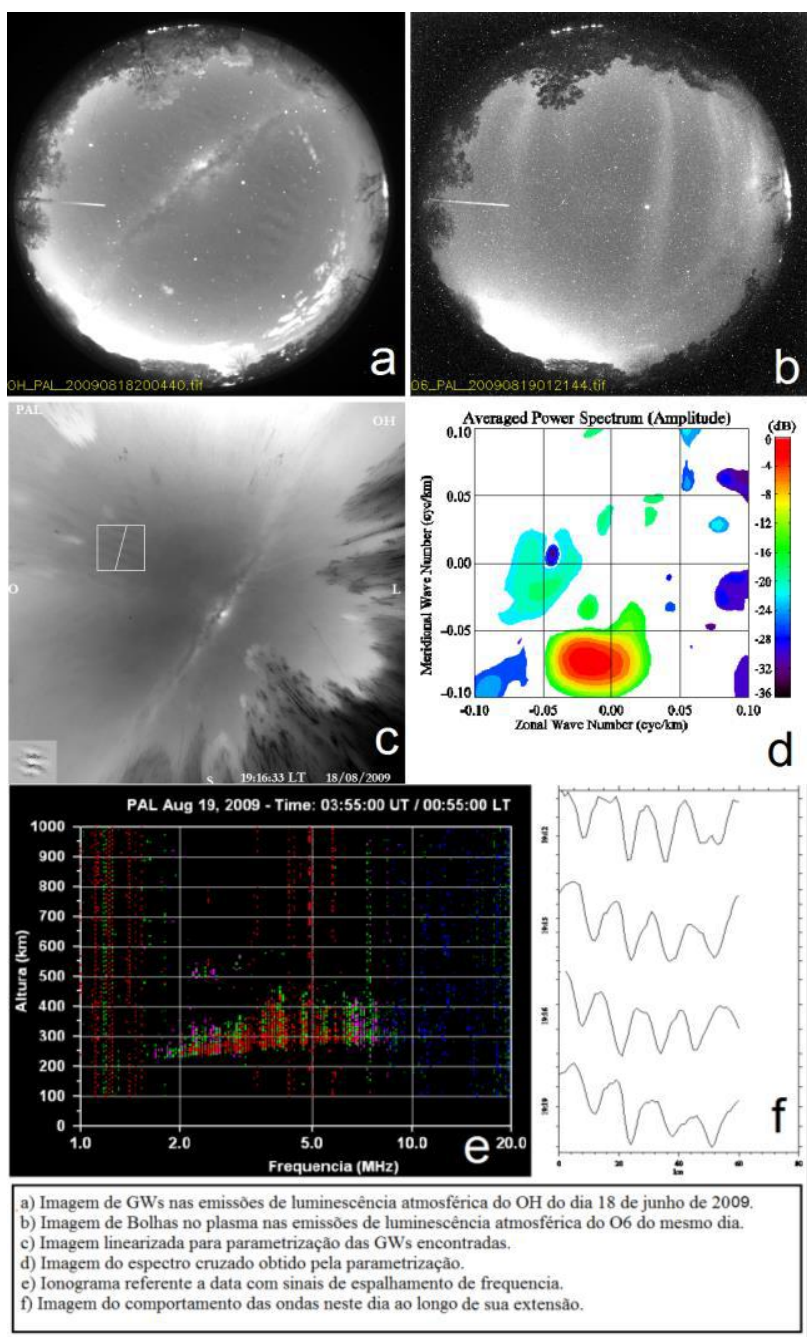

Figure 5 - Analysis results GW event observed on June 18, 2009 on the Palmas station.

In the graphs in panels of Figure 6 are shown four parameters obtained from 8-day-wave events. These graphs do not show statistical values, but summarizes the values obtained for each parameter GW. These charts pertain to the extracted parameters of the $\mathrm{OH}$ band emission images.
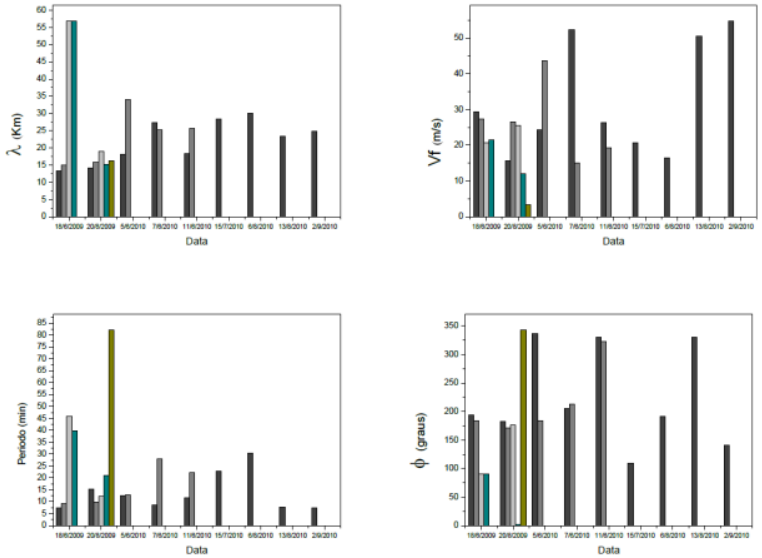

Figura 6 - GW's parameters obtained in 8 events at Palmas. Indicate $(\lambda)$ the horizontal wavelenght, (Vf) phase velocity, and $(\Phi)$ the azimuthal angle.

In the panels of Figure 7 we present a case when irregularities were observed simultaneously by all the instruments installed at the low-latitude station of São José dos Campos.
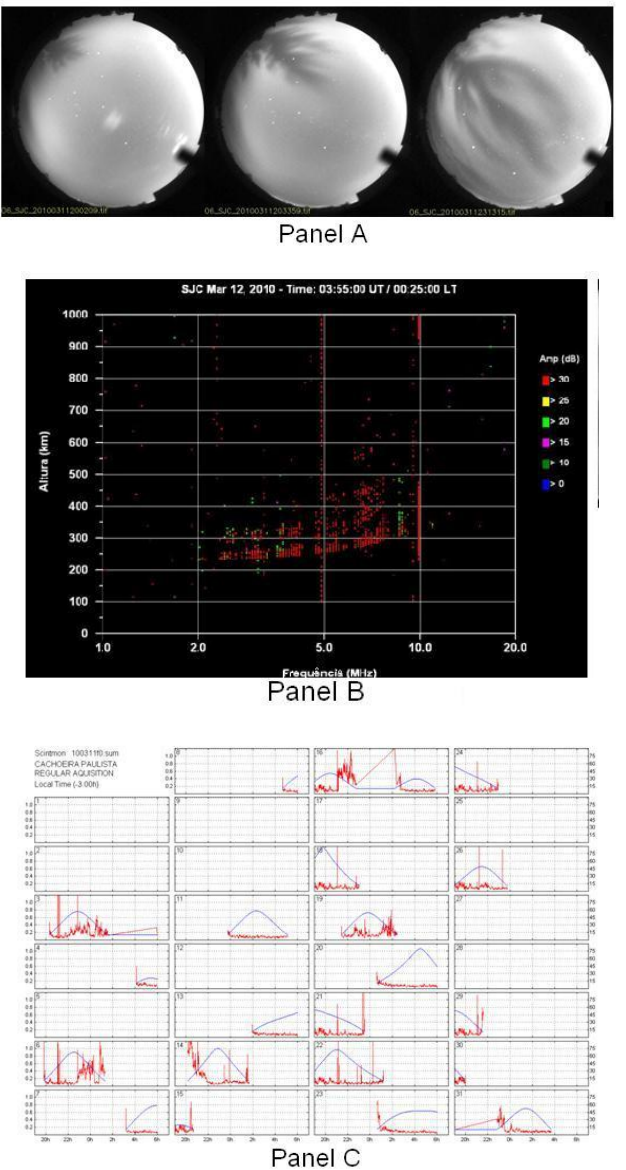


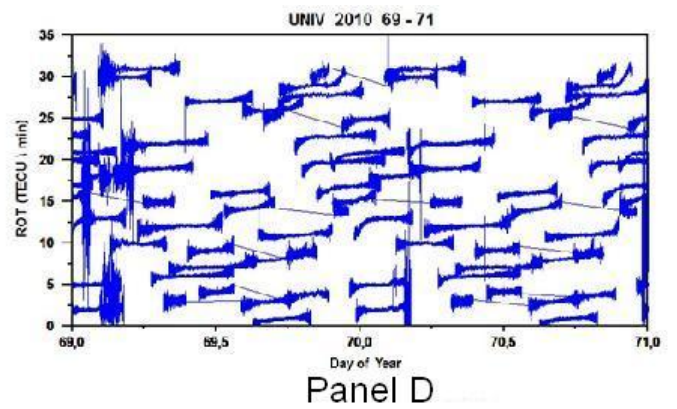

Figure 7 - Panel A: large scale plasma depleted structures detected by the all-sky imager; Panel B: spread- $F$ in the ionograms registered by the digital ionosonde; Panel C: amplitude scintillation index S4 registered by the scintillation monitor; Panel $D$ : rate of TEC variation estimated by the dual frequency GPS receiver.

\section{Discussions and Conclusions}

Wave events were identified in three different emission lines preceding and bubbles, as seen in the example of Figure 6 for the palms station. The possible relationship between the occurrence of GW's and the start of the bubbles was identified in eight days of events. These days there is a great probability that GW's contributed in some way in the generation of irregularities in the ionospheric plasma, as some authors have suggested in the literature. However, in most events the images obtained from $\mathrm{O} 5$ and $\mathrm{O} 6$ filters were etched with a very large time interval, disabling the parameterization of ondas.Sendo thus only $\mathrm{GWs}$ in the $\mathrm{OH}$ line may be analyzed and the propagation was not fully confirmed. In this example the results strongly suggest images of propagation of GWs from mesosfera to the ionosphere and, shortly thereafter, the top of the HI-bubbles $630.0 \mathrm{~nm}$ images and / or data ionosondes. However, in any of the selected events to Palmas were identified then the occurrence of bubbles and irregularities in the images and radio instruments installed at the low latitude station in São José dos Campos. With this, we can not identify any events that could have triggered these bubbles on the equator and its subsequent expansion to the region of more distant latitudes. However, one possible explanation for this may be the fact that the tests were made for the period of low solar activity.
The observations in the night from March 11 to 12, 2010, as showed in the panels of Figure 5, present the simultaneity of irregularities with different scale sizes. The results reveal the coexistence of irregularities from hundreds of kilometer to hundreds of meter. The airglow observations and the spread- $F$ on ionograms reveal the presence of large scale structures (hundreds of kilometer scale size irregularities). The primary instability processes that give origin to the irregularities can be followed by other secondary plasma instabilities, which can lead to a cascading process and to originate a wide spectrum of irregularity structures (DE PAULA et al., 2010). For example, during the generation/growth phase of plasma bubbles, few kilometer scale structures causes the signatures in the TEC data, as observed from the ROT plots in panel C. Thus, we can consider that major irregularities tend to cascade to minor irregularities structures, such as the smaller (hundred meter) scale irregularities causing the fluctuations in the GPS L1 amplitude signals (S4 index in panel D). According to Muralikrishna [2000], small scale irregularities associated with large scale structures can be generated in a region of downward electron density gradients, since the ambient electric field is also downward. For the irregularities to be observed at the latitudes of São José dos Campos, it means that they were generate at the dip equator, and reached the apex height that expanded them along the magnetic field lines until the latitudes of the EIA. As the ambient electron density is larger surrounding the EIA, it also creates conditions favorable to the generation of irregularities with different scale sizes. However, an important aspect that must be investigated in the continuation of this study is the fact that, the present observations were carried out during a geomagnetic quiet day at solar minimum period, and simultaneous observations of this kind of irregularities during the period analyzed here is extremely rare.

\section{Acknowledgments}

P. R. P. Meibach-Rosa thanks the support from São Paulo Research Foundation (FAPESP) under grant number 2013/12013-0 and 2014/19588-0. 


\section{References}

ARAUJO-PRADERE, E. A., et al. Some characteristics of the ionospheric behavior during solar cycle 23/24 minimum, Solar Phys., 274, 439, doi:10.1007/s11207011-9728-3, 2011.

ABDU, M.A. Outstanding problems in the equatorial ionosphere-thermosphere electrodynamics relevant to spread F. Journal of Atmospheric and Solar-Terrestrial Physics, v. 63, p. 869-884, 2001.

DE PAULA E.R., et al. Magnetic conjugate point observations of kilometer and hundred-meter scale irregularities and zonal drifts. Journal of Geophysical Research, doi:10.1029/2010JA015383, 2010.

KELLEY, M.C. The Earth's ionosphere. San Diego: Academic Press, 1989, 486p.

Liu, L., et al.The ionosphere under extremely prolonged low solar activity, , 116, A04320, doi:10.1029/2010JA016296, 2011

Liu, L., et al. Comparative study of the equatorial ionosphere over Jicamarca during recent two solar minima, Journal Geophys Researches, 117, A01315, doi:10.1029/2011JA017215, 2012.

MUELLA, M.T.A.H., et al. Scintillation-producing Fresnelscale irregularities associated with the regions of steepest TEC gradients adjacent to the equatorial ionization anomaly. Journal of Geophysical Research, 115, A03301, doi:10.1029/2009JA014788, 2010.

MURALIKRISHNA, P. F-region electron density irregularities during the development of equatorial plasma bubbles, Geofisica Internacional, 39, 117-125, 2000.

SALOMON, S. C., et al. The anomalous ionosphere between solar cycles 23 and 24. Journal of Geophysical Research, vol. 118, 6524-6535, doi:10.1002/jgra.50561, 2013

SHUNK, R.W.; NAGY, A. Ionospheres: Physics, Plasma Physics and Chemistry. Cambridge: Cambridge University Press, 2000. 